\title{
ANÁLISE DOS PRODUTOS ALIMENTÍCIOS APRESENTADOS NAS PROPAGANDAS DOS CANAIS INFANTIS DE TELEVISÃO POR ASSINATURA
}

\author{
ANALYSIS OF ADVERTISING FOOD PRODUCTS PRESENTED AT CHILDREN'S \\ CABLE TV CHANNELS
}

\author{
Alessandra Ledo ${ }^{1}$ \\ Daniela Maria Alves Chaud ${ }^{2}$ \\ Edeli Simioni de Abreu $^{3}$
}

\begin{abstract}
Resumo: As empresas alimentícias, historicamente, investem ferozmente na divulgação de produtos, muitos deles alimentos de calorias-vazias, ricos em açúcar e gorduras. Os comerciais, tendo a criança como público-alvo, vêm acarretando diversas inquietações de órgãos e de pesquisadores. Objetivo: Avaliar as propagandas e o valor nutricional dos produtos alimentícios apresentados em propagandas exibidas nos canais infantis de TV por assinatura. Foi realizada a gravação simultânea não consecutiva, por duas semanas, de três canais infantis de TV por assinatura $(A, B$ e $C)$. A análise dos dados consistiu na verificação daqueles dos produtos, alimentícios ou não, para posterior análise das informações nutricionais, além do cumprimento da legislação vigente. As crianças e os adolescentes que assistiram a essa programação estiveram expostos a uma alta carga de anúncios, principalmente os relacionados a brinquedos e produtos alimentícios. Entre os produtos alimentícios que mais foram anunciados destacamse os biscoitos no Canal $B$ (1aㅡ semana, 28 aparições) e refrigerante (19 aparições, Canal C, 2ª semana). Com relação aos nutrientes, notou-se que as gorduras e o açúcar, analisado de acordo com a lista de ingredientes dispostos nos rótulos desses produtos, estão em quantidades elevadas. Além disso, os anunciantes se utilizam de meios apelativos para atrair a atenção do espectador. É necessária uma fiscalização e controle mais efetivos por parte dos órgãos públicos com relação às propagandas e chamadas exibidas na televisão, uma vez que estas podem exercer importante influência nas escolhas alimentares, principalmente no público infantil, período no qual há a formação das preferências alimentares.
\end{abstract}

Palavras-chave: Propagandas; televisão; criança; consumidor.

Abstract: Food companies historically invest fiercely in the promotion of products and many of them are food-empty calories, high in sugar and fats. Commercial, taking the child as target audience, come causing several concerns to organs and researchers. Objective: evaluate advertisements and nutritional value of food products displayed in the children's channels pay TV. For such, a simultaneous recording of three channels of this type was made ( $A, B$ and $C)$, in a not consecutively way and for a period of two weeks. The data analysis consisted in verifying those associated with food products for subsequent dietary review, in addition to compliance with current legislation for food advertisements and industrialized beverages. Food products that were most advertised stand out biscuits on Channel B (1st week, 28 appearances) and soda (19 appearances, Channel C, 2nd week). Regarding to nutrients, it was noticed that fats and sugar, analyzed according to the list of ingredients of those labels, are found in high amounts in foods marketed. In addition, advertisers make use of appealing ways to attract the attention of the listener. Thus, it can be concluded that a monitoring and more effective control by the public authorities with regard to advertisements and calls displayed on television is needed, since the exposed amount can exert important influence on food choices, especially in the children's audience, where individual development and food preferences are being built.

Keywords: Advertisements; television; child; consumer.

\footnotetext{
1 Nutricionista recém egressa do Curso de Nutrição do Centro de Ciências Biológicas e da Saúde Universidade Presbiteriana Mackenzie. E-mail: alessandra.ledo@gmail.com.

2 Professor Adjunto do Centro de Ciências Biológicas e da Saúde - Curso de Nutrição - Universidade Presbiteriana Mackenzie, Brasil. E-mail: daniela.chaud@mackenzie.br.

3 Professor Adjunto do Centro de Ciências Biológicas e da Saúde - Curso de Nutrição - Universidade Presbiteriana Mackenzie, Brasil. E-mail: edelisabreu@gmail.com.

Revista Univap - revista.univap.br

São José dos Campos-SP-Brasil, v. 25, n. 47, jul. 2019. ISSN 2237-1753
} 


\section{INTRODUÇÃO}

A comunicação voltada ao público infantil apresentou grande destaque a partir do momento que se descobriu que a criança é um potencial consumidor e capaz de influenciar os adultos no ato da compra (SILVEIRA, 2015).

Do ponto de vista do marketing, abranger o público infanto-juvenil por meio da promoção comercial desperta um elevado interesse, uma vez que são notados não apenas como atuais, mas também como futuros consumidores (SILVA et al, 2017). Nesse contexto, a regulamentação da propaganda e da publicidade de alimentos pode assumir um papel estratégico como medida de proteção, particularmente voltada para o público mais vulnerável aos apelos promocionais, como o infantil (HENRIQUES, 2014).

Por esse motivo, diversas ações vêm sendo realizadas como forma de controlar as propagandas, gerando, inclusive, várias discussões entre os profissionais de marketing, nutricionistas e outros profissionais e associações relacionadas. Foi incluído em 2006 no Conselho Nacional de Autorregulamentação Publicitária CONAR (COMITÊ..., 2006), novas normas éticas no código brasileiro de alimentos e bebidas realizadas pela publicidade. Cabe a este órgão reger os princípios básicos que definem a ética da publicidade no Brasil. O CONAR é uma organização nãogovernamental que tem como objetivo a promoção da liberdade de expressão publicitária e a defesa dos direitos constitucionais dos anúncios comerciais. As denúncias são realizadas pelos próprios consumidores e estas são levadas ao Conselho de Ética. Se a denúncia, após julgada, tiver procedência, a propaganda pode deixar de ser exibida ou solicitada correções destas (CONSELHO..., 2006).

Como exemplo de outro órgão que se preocupa com estas questões, pode-se citar o Instituto ALANA. É uma organização sem fins lucrativos que tem por objetivo promover assistência social, visando a uma melhora na qualidade de vida, sem utilizar de qualquer forma de preconceito ou discriminação. Além disso, o instituto desenvolve atividades em defesa dos direitos das crianças e adolescentes, considerando, inclusive, as relações de consumo em geral. Como exemplo dessa última atividade, em 2006 foi criado o Projeto Criança e Consumo para debater e indicar soluções que minimizam os efeitos negativos, resultado do investimento da mercantilização da infância e da adolescência (considerando como exemplo a elevação da obesidade, a violência contra a criança, a erotização, entre outros), tendo como meta proibir legal e expressamente essas ações (VIVARTA, 2009).

Além desses órgãos, os problemas crescentes com relação ao aumento de peso da população no Brasil têm acarretado algumas iniciativas por parte, inclusive, do governo, com o intuito de controlar as ações promocionais de alimentos. Desde 2006, a ANVISA (Agência Nacional de Vigilância Sanitária) vem discutindo a regulamentação da publicidade de alimentos e bebidas não saudáveis, até mesmo para crianças. Ainda 
naquele ano, a agência desempenhou uma audiência pública, com a presença do IDEC (Instituto de Defesa do Consumidor), anunciando que ainda em 2006 editaria uma resolução. A proposta da ANVISA era mais abrangente e propunha definir com nitidez quais são os padrões que levariam a considerar um alimento ou uma bebida como saudável, como também os horários nos quais os anúncios poderiam ou não ser veiculados. Ainda na resolução propunha o veto do uso de desenhos, personagens e a oferta de brindes associados a alimentos e bebidas não saudáveis (DIAS, 2011).

Vale lembrar que, desde 1988, a Constituição Federal e a promulgação do Estatuto da Criança e do Adolescente (ECA) possibilitaram um novo olhar sobre a infância e a adolescência, ao incluir diretrizes da Convenção Internacional dos Direitos da Criança, que foram aprovadas por unanimidade na Assembleia Geral das Nações Unidas e assinadas pelo Brasil, em 26 de janeiro de 1990. Integrante da estrutura básica da Secretaria de Direitos Humanos da Presidência da República (SDH/PR), criado pela Lei n. 8.242 de 12 de outubro de 1991, o Conselho Nacional dos Direitos da Criança e do Adolescente - CONANDA é um órgão colegiado de caráter normativo e deliberativo de composição paritária entre governo e sociedade civil. Esse órgão tem como dever e competência, prevista na Constituição, de zelar pela devida e eficiente aplicação das normas de proteção às crianças e adolescentes no Brasil (BRASIL, 1991).

Foi também divulgado pelo Ministério da Saúde um informe sobre a Resolução $n^{\circ}$ 163/2014 do CONANDA que "dispõe sobre a abusividade do direcionamento da publicidade e de comunicação mercadológica à criança e ao adolescente", cuja intenção seja de persuadi-la para o consumo de qualquer produto ou serviço (CONSELHO..., 2014).

Tendo em vista as premissas supracitadas, justifica-se a realização deste trabalho, cujo objetivo foi avaliar a frequência e o valor nutricional de produtos alimentícios apresentados em propagandas exibidas nos canais infantis de TV por assinatura.

\section{METODOLOGIA}

O estudo foi de delineamento transversal, com coleta de dados primários, realizado no município de São Paulo, entre os meses de novembro e dezembro de 2011. A coleta de dados foi por meio de gravação simultânea das programações dos canais infantis de TV por assinatura (A, B e C). Foram 14 dias, não consecutivos, no período da manhã, das $8 \mathrm{~h}$ às $12 \mathrm{~h}$.

A análise dos dados consistiu na observação e tomada de nota dos diferentes tipos de propagandas apresentadas, sendo tabuladas de acordo com o tipo: alimentos, bebidas, brinquedos, e outros (aparelhos eletrônicos, beleza, brinquedos, calçados, entretenimento, utilidade pública ou governamental, higiene e limpeza, medicamento e 
curativos, loja e shopping, material escolar e papelaria, hipermercados, educativo e música, músicas e clipes, linha de produtos e programação, comerciais promocionais e instituições financeiras). A partir da obtenção desses, foram verificadas as propagandas relacionadas a produtos alimentícios e bebidas, sendo posteriormente separadas em categorias, como pode ser observado nas Tabelas 1 e 2:

Tabela 1 - Classificação utilizada para análise dos produtos alimentícios apresentados. Alimentos Tipos

\begin{tabular}{ll}
\hline Azeites & Azeite 1 \\
Biscoitos & Biscoito 1, Biscoito 2 \\
Minibolos & Minibolo 1; Minibolo 2; Minibolo 3 \\
Cereais matinais & Cereal matinal 1 \\
Chocolate & Chocolate 1 \\
Guloseimas & Bala 1 \\
logurtes & logurte 1 \\
Panetones & Panetone 1; Panetone 2 \\
Salgados & Salgado 1; Salgado 2 \\
Sobremesa & Sobremesa \\
Fast food & Fast food; Fast food + brinde; Fast food: refeição completa + brinde
\end{tabular}
Fonte: Os autores, 2011.

Tabela 2 - Classificação utilizada para análise das bebidas apresentadas.

\begin{tabular}{ll}
\hline \multicolumn{1}{c}{ Bebidas } & \multicolumn{1}{c}{ Tipos } \\
\hline Suco artificial & Suco artificial 1a; Suco artificial 1b \\
Achocolatado & Achocolatado \\
Bebida fermentada (láctea) & Bebida fermentada \\
Refrigerante & Refrigerante \\
\hline
\end{tabular}

Fonte: Os autores, 2011.

Foram também analisados, com dados obtidos da rotulagem, os ingredientes utilizados para verificação do açúcar presente nos produtos e a informação nutricional, sendo selecionados para análise o valor energético, a gordura saturada, trans e o sódio. 
Ao final, foi realizada análise dos comerciais alimentícios quanto ao cumprimento das normas estabelecidas na legislação com relação às propagandas de alimentos e bebidas.

\section{RESULTADOS E DISCUSSÃO}

Dos resultados obtidos, pelo exposto na Figura 1, os comerciais de brinquedos são os que apresentam maior média de aparições em todos os canais, especialmente na segunda semana. Sugere-se que esse resultado seja devido à proximidade da época festiva em que foram coletados os dados (Natal). Por outro lado, analisando o item classificado como "Outros", verifica-se que este prevaleceu na primeira semana, se comparado aos brinquedos, nos três canais analisados. Ainda, nesse mesmo gráfico, os alimentos e as bebidas apresentaram, em média, um valor relativamente inferior, se comparados aos outros grupos.

Figura 1 - Média de aparição diária dos comerciais apresentados e separados por tipo, nos três canais, em cada semana.

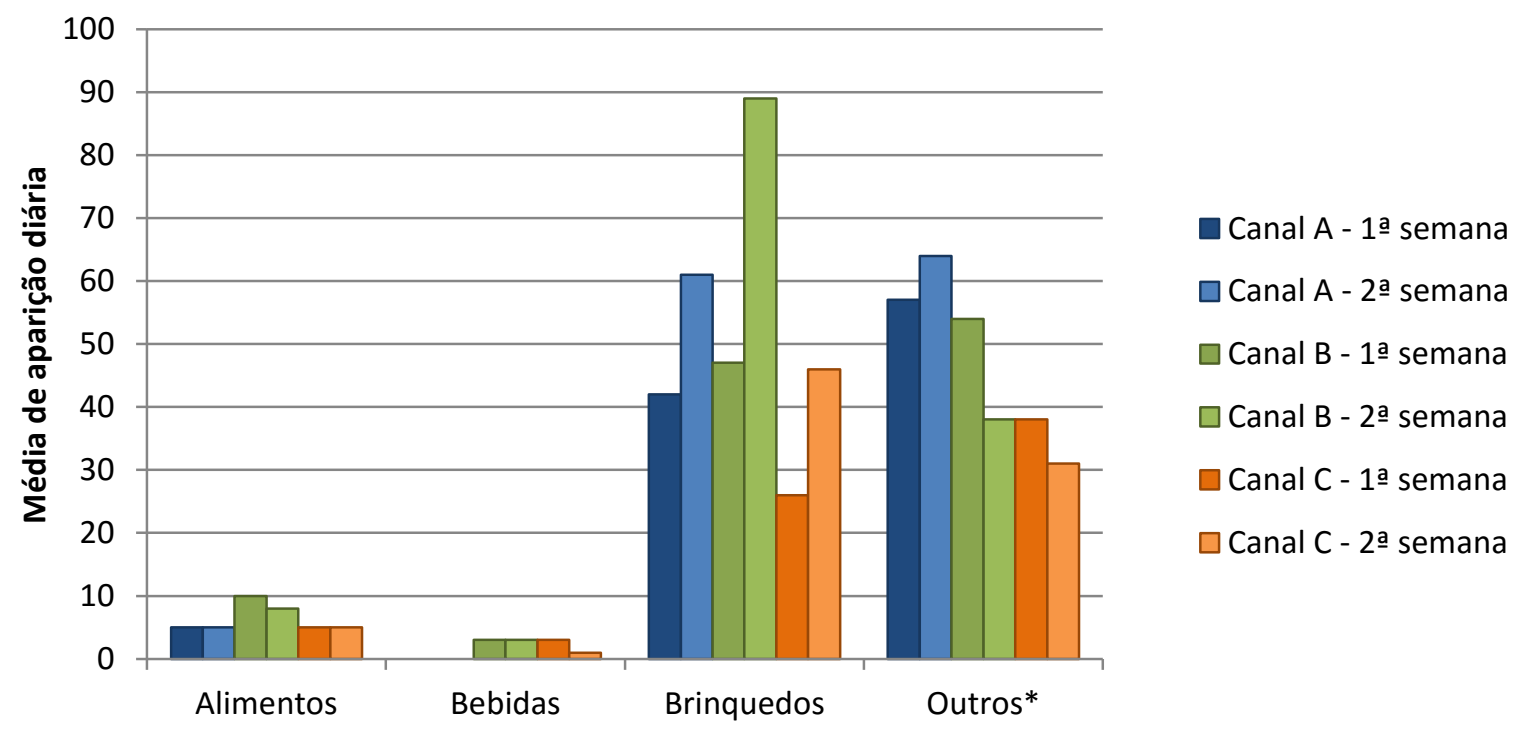

Fonte: Os autores, 2011.

Porém, conforme a Figura 2 e Figura 3, relacionadas aos comerciais de alimentos e bebidas, classificados de acordo com suas características, foi possível verificar que, durante as 4 horas diárias que os canais foram gravados, estes tiveram uma quantidade considerável de aparições por semana. 
Figura 2 - Aparições das propagandas de alimentos classificadas por grupo, apresentadas por semana e separadas pelo canal correspondente.

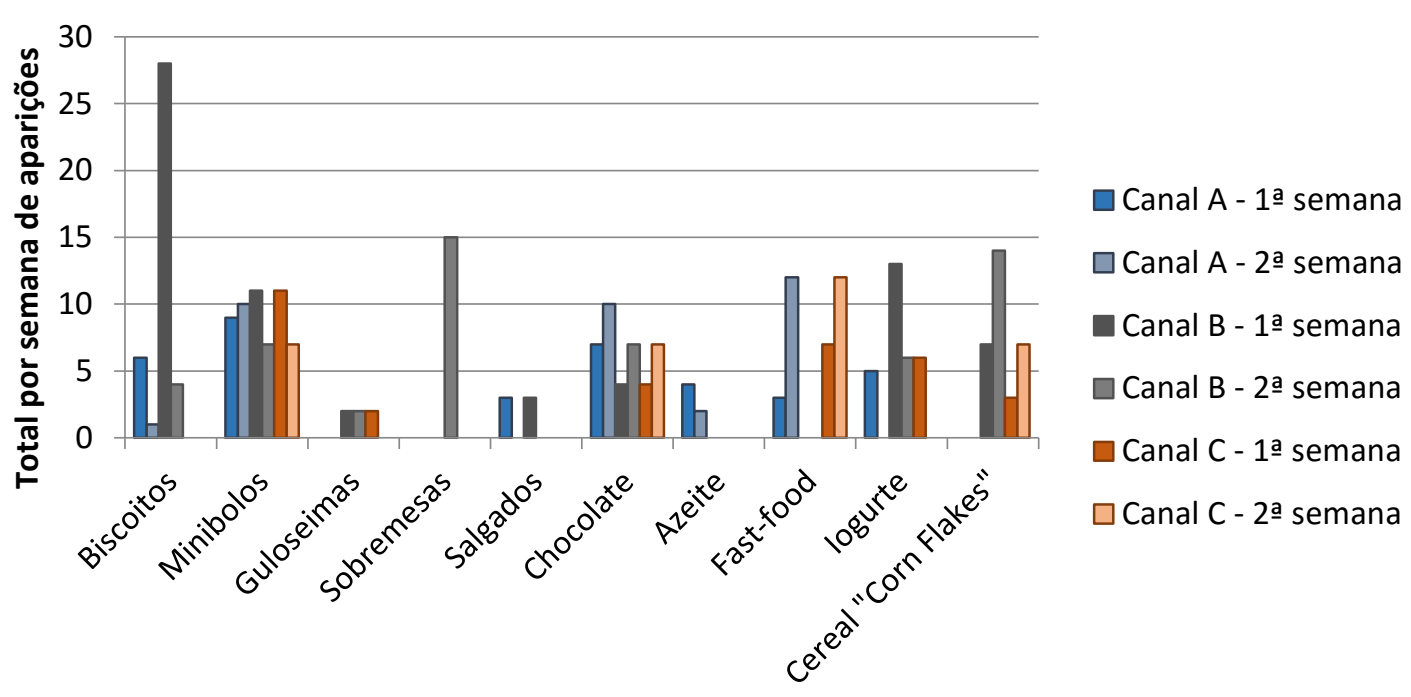

Fonte: Os autores, 2011.

Figura 3 - Aparições das propagandas de bebidas classificadas por grupo, apresentadas por semana e separadas pelo canal correspondente.

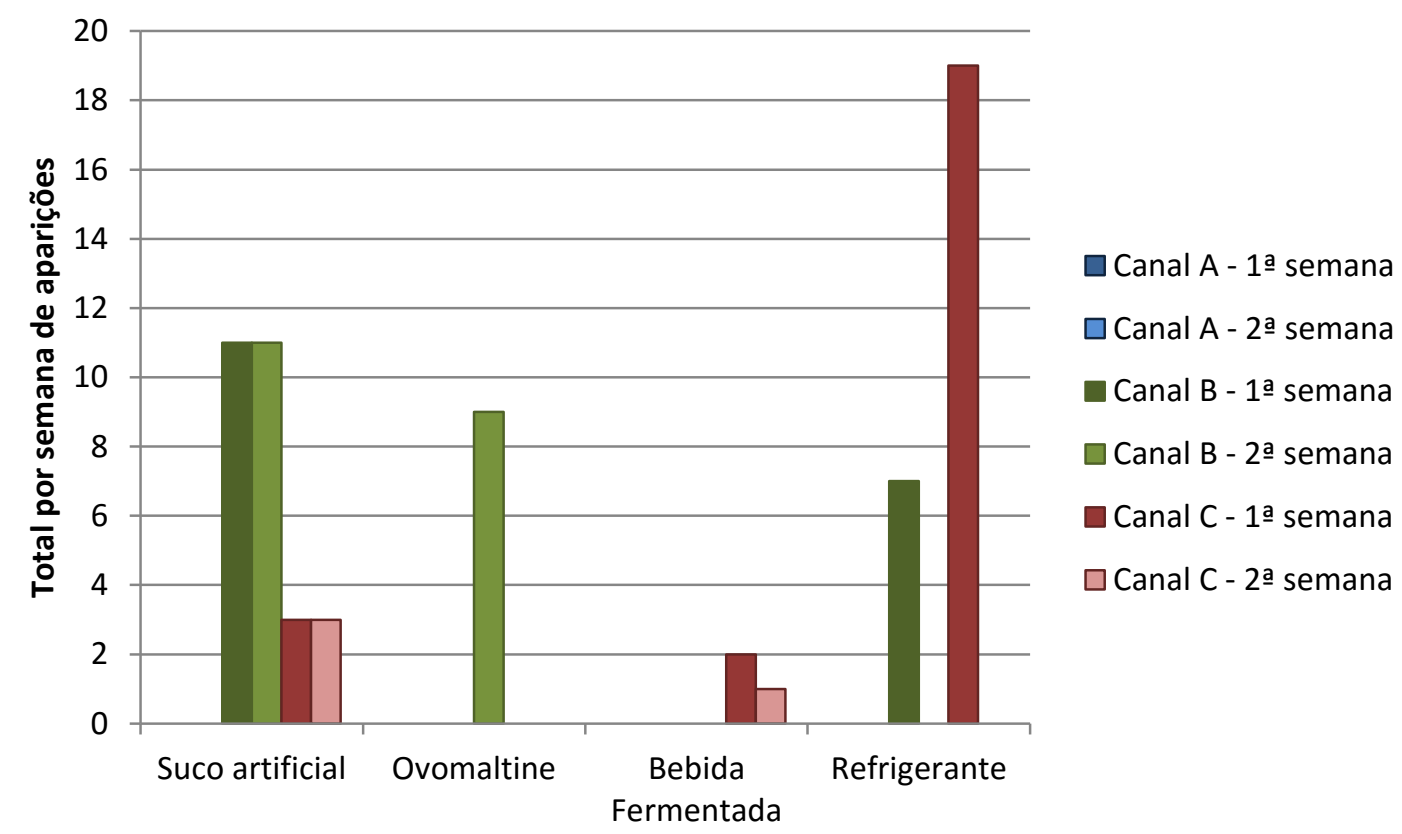

Fonte: Os autores, 2011.

De acordo com os dados obtidos na Figura 2, os produtos alimentícios que apareceram nas propagandas dos três canais foram os bolos e chocolates. Observouse quantidade significativa de propaganda de biscoitos, com maior expressividade na $1^{\text {a }}$ semana do Canal $B$. Também foi possível verificar que no Canal $B$, durante as 2 semanas de análise, não constaram comercias de fast-food, porém quanto às sobremesas foi o único em que esta foi exibida. 
Sobre os comerciais de bebidas (Figura 3), o Canal $A$ foi o único que não apresentou este produto em nenhum dos dias analisados. Já, o refrigerante apareceu 19 vezes, na $2^{\underline{a}}$ semana do Canal $C$.

Considerando os produtos alimentícios anunciados, os valores de energia encontrados por de $100 \mathrm{~g}$ de cada produto são abaixo apresentados (Tabela 3 e 4).

Tabela 3 - Valor energético dos produtos apresentados, considerando $100 \mathrm{~g}$ do produto.

\begin{tabular}{ll}
\hline \multicolumn{1}{c}{ Alimentos } & Valor energético (porção 100g) \\
\hline Azeite & $830 \mathrm{kcal}$ \\
Bala & $385 \mathrm{kcal}$ \\
Biscoito 1 & $474 \mathrm{kcal}$ \\
Biscoito 2 & $470 \mathrm{kcal}$ \\
Minibolo 1 & $320 \mathrm{kcal}$ \\
Minibolo 2 & $360 \mathrm{kcal}$ \\
Minibolo 3 & $403 \mathrm{kcal}$ \\
Cereal matinal 1 & $363 \mathrm{kcal}$ \\
Chocolate & $545 \mathrm{kcal}$ \\
logurte & $110 \mathrm{kcal}$ \\
Panetone 1 & $297 \mathrm{kcal}$ \\
Panetone 2 & $444 \mathrm{kcal}$ \\
Salgadinho 1 & $417 \mathrm{kcal}$ \\
Salgadinho 2a & $392 \mathrm{kcal}$ \\
Salgadinho 2b & $380 \mathrm{kcal}$ \\
Sobremesa & $383 \mathrm{kcal}$ \\
\hline
\end{tabular}

Fonte: Os autores, 2011.

Tabela 4 - Valor energético das bebidas apresentadas, considerando $100 \mathrm{~g}$ ou $100 \mathrm{ml}$ do produto.

\begin{tabular}{lc}
\hline \multicolumn{1}{c}{ Bebida } & Valor energético (porção $\mathbf{1 0 0} \mathbf{~ g / 1 0 0 ~} \mathbf{~ m l}$ ) \\
\hline Suco artificial 1a & $350 \mathrm{kcal}$ \\
Suco artificial 1b & $350 \mathrm{kcal}$ \\
Achocolatado & $383 \mathrm{kcal}$ \\
Bebida fermentada & $55 \mathrm{kcal}$ \\
Refrigerante & $43 \mathrm{kcal}$ \\
\hline
\end{tabular}

Fonte: Os autores, 2011.

Conforme demonstrado, salienta-se que os alimentos que apresentaram menor valor energético foram o iogurte (110 kcal) e o panetone 1 (297 kcal), sendo o maior deles representado pelo azeite, com $830 \mathrm{kcal}$ e o chocolate, com $545 \mathrm{kcal}$. Porém, o azeite merece uma ressalva, pois o cálculo foi realizado considerando porção de $100 \mathrm{~g}$ e sabe-se que este valor não corresponde ao consumo diário da população. Além disso, do ponto de vista nutricional e defendido por muitos autores, compostos como 
vitaminas lipossolúveis, ácidos graxos insaturados e fenólicos estão presentes no azeite de oliva, conjunto esse benéfico para à saúde dos indivíduos que auxiliam, por exemplo, na manutenção equilibrada entre os colesteróis HDL e LDL, na prevenção de DCNT, câncer e doenças cardiovasculares (CAVALHEIRO et al., 2014). Já, com relação às bebidas, o refrigerante foi o que obteve menor valor (43 kcal), seguido da bebida fermentada com $55 \mathrm{kcal}$, restando com os maiores valores energéticos 0 achocolatado e o suco artificial ( $350 \mathrm{kcal}$ e $383 \mathrm{kcal}$, respectivamente). Sugere-se que a diferença nos valores seja devido à forma de comercialização, pois estes últimos são em pó, sendo mais concentrados em apresentação, não compatível ao consumo se comparados às outras bebidas anunciadas.

Ainda com relação aos valores energéticos, foram apresentados nos Canais $A$ e C propagandas de fast-food (Tabela 5). Porém, com exceção do que aparece em primeiro lugar, nessa tabela, as informações disponíveis para consulta não descrevem a porção exata considerada para a formulação da tabela nutricional, impedindo que seja transformada para $100 \mathrm{~g}$ do produto. Para simples comparação de dados, todas as informações desse grupo foram descritas na forma em que se apresentam para consulta.

Tabela 5 - Valor energético dos alimentos que compõem a refeição do fast-food apresentada no anúncio.

\begin{tabular}{lll}
\hline \multicolumn{1}{c}{ Comerciais } & \multicolumn{1}{c}{ Alimento / Valor energético } & TOTAL \\
\hline & ${ }^{*}$ Condimentos e extras: 29 kcal & \\
Fast-food (composto por lanche em porção & ${ }^{*}$ Pão italiano, alface, tomate, & \\
compatível com o consumo de um adulto) & $\begin{array}{l}\text { cebola, pimentão e azeitonas: } 447 \\
\text { kcal }\end{array}$ & 862 kcal \\
& ${ }^{*}$ Carne: 386 kcal
\end{tabular}

Fast-food com brinde (composto por lanche, batata frita, fruta e suco em porções compatíveis com o consumo infantil)

Fast-food: refeição completa e suco compatíveis ao consumo infantil + brinde
* Sanduíche: $245 \mathrm{kcal}$

* Batata frita: $87 \mathrm{kcal}$

* Fruta: $25 \mathrm{kcal}$ 491 kcal

* Suco - pêssego: 134 kcal
456 kcal

* Iscas de filé de frango: $120 \mathrm{kcal}$

* Salada de alface e tomate: $9 \mathrm{kcal}$

* Suco - pêssego: $111 \mathrm{kcal}$

Fonte: Os autores, 2011.

Pelo exposto, verificou-se que a refeição de mais elevada densidade calórica possui $862 \mathrm{kcal}$. A provável explicação para o fato é que este anunciante, apesar de ser exibido em um canal infantil, tem seu foco no público adolescente e adulto, tendo como consequência lanches de maior densidade calórica em seu cardápio, se comparado aos demais. Considera-se, portanto, um anúncio inapropriado para o 
público infantil, o qual pode estimular o consumo energético superior ao compatível com uma refeição para tal faixa etária. Pode-se considerar que esse anúncio corrobora com o desenvolvimento da obesidade infantil.

A Tabela 6 e a Tabela 7 referem-se aos valores encontrados de gordura saturada nos alimentos e bebidas anunciados.

Tabela 6 - Valores de gorduras saturadas dos produtos alimentícios anunciados nos canais de TV por assinatura.

\begin{tabular}{lc}
\hline \multicolumn{1}{c}{ Alimentos } & Gordura saturada (porção $\mathbf{1 0 0 ~ g ) ~}$ \\
\hline Azeite & $14,6 \mathrm{~g}$ \\
Bala & $0 \mathrm{~g}$ \\
Biscoito 1 & $8,3 \mathrm{~g}$ \\
Biscoito 2 & $6 \mathrm{~g}$ \\
Minibolo 1 & $8,3 \mathrm{~g}$ \\
Minibolo 2 & $4 \mathrm{~g}$ \\
Minibolo 3 & $12,1 \mathrm{~g}$ \\
Cereal matinal 1 & $0 \mathrm{~g}$ \\
Chocolate & $14 \mathrm{~g}$ \\
logurte & $2 \mathrm{~g}$ \\
Panetone 1 & $8,7 \mathrm{~g}$ \\
Panetone 2 & $9,4 \mathrm{~g}$ \\
Salgado 1 & $4,3 \mathrm{~g}$ \\
Salgado 2a & $8 \mathrm{~g}$ \\
Salgado 2b & $6,8 \mathrm{~g}$ \\
Sobremesa & $0,8 \mathrm{~g}$ \\
\hline
\end{tabular}

Fonte: Os autores, 2011.

Tabela 7 - Valores de gorduras saturadas das bebidas anunciadas nos canais de TV por assinatura.

\begin{tabular}{lc}
\hline \multicolumn{1}{c}{ Bebidas } & Gordura saturada (poção $\mathbf{1 0 0} \mathbf{~ g} / \mathbf{1 0 0} \mathbf{~ m l}$ ) \\
\hline Suco artificial 1a & "Não há quantidade significativa" \\
Suco artificial $1 \mathrm{~b}$ & "Não há quantidade significativa" \\
Achocolatado & $0,7 \mathrm{~g}$ \\
Bebida fermentada & "Não há quantidade significativa" \\
Refrigerante & "Não há quantidade significativa" \\
\hline
\end{tabular}

Fonte: Os autores, 2011.

De acordo com a RDC no 24, de 15 de junho de 2010 (BRASIL, 2010), "alimento com quantidade elevada de gordura saturada é aquele que possui em sua composição uma quantidade igual ou superior a $5 \mathrm{~g}$ de gordura saturada por $100 \mathrm{~g}$ ou $2,5 \mathrm{~g}$ por $100 \mathrm{ml}$ na forma como está à venda". Sendo assim, dos 16 alimentos selecionados para análise do rótulo, 68,75\% são considerados com quantidade elevada de gordura saturada, destacando-se novamente o azeite, com 14,6g e o chocolate, com 14g. 
Ainda assim, vale ressaltar que $100 \mathrm{~g}$ não correspondem ao consumo real de azeite e este possui propriedades favoráveis à saúde, como já citado anteriormente. Porém, pelos dados obtidos na rotulagem das bebidas, as gorduras saturadas não são significativas na porção considerada na tabela nutricional, com exceção apenas do achocolatado que apresenta um teor a baixo de gordura saturada em $100 \mathrm{~g}$ da bebida $(0,7 \mathrm{~g})$. Vale ressaltar que, segundo a legislação, o rótulo pode conter a informação apresentada quando o valor obtido na análise for menor ou igual a 0,2g.

Considerada a porção apresentada para consumo, sendo essas apresentadas nos comerciais de fast-food (Tabela 8), verifica-se que mais uma vez o primeiro listado nessa tabela apresenta gorduras saturadas em maior (e elevada) quantidade $(10,9 \mathrm{~g}) \mathrm{e}$ o último possui o menor valor $(2,72 \mathrm{~g})$.

Tabela 8 - Valor total de gorduras saturadas dos anúncios de fast-food apresentados nos canais de TV por assinatura.

\begin{tabular}{|c|c|c|}
\hline Comerciais & Alimento / Gordura Saturada & TOTAL \\
\hline $\begin{array}{l}\text { Fast-food (composto por lanche em } \\
\text { porção compatível com o consumo } \\
\text { de um adulto) }\end{array}$ & $\begin{array}{l}{ }^{*} \text { Condimentos e extras: } 0 \mathrm{~g} \\
\text { * Pão italiano, alface, tomate, cebola, } \\
\text { pimentão e azeitonas: } 6,2 \mathrm{~g} \\
{ }^{\star} \text { Carne: } 4,7 \mathrm{~g}\end{array}$ & $10,9 \mathrm{~g}$ \\
\hline $\begin{array}{l}\text { Fast-food com brinde (composto por } \\
\text { lanche, batata frita, fruta e suco em } \\
\text { porções compatíveis com o consumo } \\
\text { infantil) }\end{array}$ & $\begin{array}{l}\text { * Sanduíche: } 3,3 \mathrm{~g} \\
\text { * Fritas: } 1,4 \mathrm{~g} \\
\text { * Fruta: } 0,1 \mathrm{~g} \\
\text { * Suco - pêssego: } 0 \mathrm{~g}\end{array}$ & $4,8 \mathrm{~g}$ \\
\hline $\begin{array}{l}\text { Fast-food: refeição completa e suco } \\
\text { compatíveis ao consumo infantil + } \\
\text { brinde }\end{array}$ & $\begin{array}{l}\text { * Arroz: } 0,96 \mathrm{~g} \\
\text { * Feijão: } 0,26 \\
\text { * Iscas de filé de frango: } 1,5 \mathrm{~g} \\
\text { * Salada de alface e tomate: } 0 \mathrm{~g} \\
\text { * Suco - pêssego: } 0 \mathrm{~g}\end{array}$ & $2,72 \mathrm{~g}$ \\
\hline
\end{tabular}

Fonte: Os autores, 2011.

Uma consideração parecida é apresentada na legislação com relação à gordura trans, podendo ser considerado no rótulo "não estabelecido", "zero" ou "não apresenta quantidade significativa" quando seu valor é menor ou igual a 0,2g. Sendo assim, a maioria dos alimentos e bebidas contém essa informação, exceto o biscoito 1 , com $0,7 \mathrm{~g}$ e o panetone 1 , com $1,4 \mathrm{~g}$, ambos sendo calculados na porção de $100 \mathrm{~g}$ do produto. Ainda assim, esses valores não são considerados elevados, de acordo com a legislação vigente.

Em estudo realizado por Mozaffarian et al. (2006), obtiveram como resultado que o aumento de $2 \%$ no consumo de energia proveniente de ácidos graxos trans eleva em $23 \%$ a ocorrência de doença arterial coronariana. Além disso, a gordura saturada tem sido utilizada como substituto para os produtos que não possuem mais em sua 
composição gorduras trans, necessitando, assim, de fiscalização pelos órgãos competentes (GAGLIARDI; FILHO; SANTOS, 2009).

Na Tabela 9, constam os valores referentes ao sódio dos produtos alimentícios anunciados, sendo a Tabela 10 as mesmas informações, considerando-se as bebidas.

Tabela 9 - Valores correspondentes ao sódio dos alimentos anunciados nas propagandas dos canais de TV por assinatura.

\begin{tabular}{lr}
\hline \multicolumn{1}{c}{ Alimentos } & Sódio (porção $\mathbf{1 0 0 ~ g ) ~}$ \\
\hline Azeite & $0 \mathrm{mg}$ \\
Bala & $70 \mathrm{mg}$ \\
Biscoitos 1 & $340 \mathrm{mg}$ \\
Biscoitos 2 & $266,7 \mathrm{mg}$ \\
Minibolo 1 & $240 \mathrm{mg}$ \\
Minibolo 2 & $166,7 \mathrm{mg}$ \\
Minibolo 3 & $150 \mathrm{mg}$ \\
Cereal matinal 1 & $586,7 \mathrm{mg}$ \\
Chocolate & $80 \mathrm{mg}$ \\
logurte & $35 \mathrm{mg}$ \\
Panetone 1 & $95 \mathrm{mg}$ \\
Panetone 2 & $109,1 \mathrm{mg}$ \\
Salgado 1 & $330 \mathrm{mg}$ \\
Salgado 2a & $988 \mathrm{mg}$ \\
Salgado 2b & $876 \mathrm{mg}$ \\
Sobremesa & $100 \mathrm{mg}$ \\
\hline
\end{tabular}

Fonte: Os autores, 2011.

Tabela 10 - Valores correspondentes ao sódio das bebidas anunciadas nas propagandas dos canais de TV por assinatura.

\begin{tabular}{lc}
\hline \multicolumn{1}{c}{ Bebidas } & Sódio (poção $\mathbf{1 0 0 ~ g ~ / ~ 1 0 0 ~ m l ) ~}$ \\
\hline Suco artificial 1a & $850 \mathrm{mg}$ \\
Suco artificial 1b & $650 \mathrm{mg}$ \\
Achocolatado & $250 \mathrm{mg}$ \\
Bebida fermentada & $28 \mathrm{mg}$ \\
Refrigerante & $7 \mathrm{mg}$ \\
\hline
\end{tabular}

Fonte: Os autores, 2011.

Para análise desse dado, na RDC oㅜ 24, de 15 de junho de 2010 (BRASIL, 2010), consta a menção (...) "o alimento com quantidade elevada de sódio é aquele que possui em sua composição uma quantidade igual ou superior a $400 \mathrm{mg}$ de sódio por $100 \mathrm{~g}$ ou $100 \mathrm{ml}$ na forma como está exposto à venda". Com isso, dos alimentos apresentados na Tabela 7, 18,75\% são classificados com elevada quantidade de sódio. Porém, com relação às bebidas (Tabela 8), esta classificação é válida para 60\% dos produtos anunciados, não obstante, os sucos estejam apresentados sob sua forma em pó, é possível o consumo completo do produto, tendo em vista o país 
tropical e estação compatível com maior necessidade de hidratação e consumo hídrico, sendo que produtos aromatizados podem ser consumidos em sua totalidade durante o dia (1L de produto pronto).

Já, quanto às propagandas de fast-food (Tabela 11), os valores totais de sódio ultrapassaram os já considerados elevados.

Tabela 11 - Valores de sódio correspondentes aos comerciais de fast-food anunciados nos canais de TV por assinatura.

\begin{tabular}{|c|c|c|}
\hline Comerciais & Alimento / Sódio & TOTAL \\
\hline $\begin{array}{l}\text { Fast-food (composto por lanche em } \\
\text { porção compatível com o consumo de } \\
\text { um adulto) }\end{array}$ & $\begin{array}{l}\text { * Condimentos e extras: } 213 \mathrm{mg} \\
\text { * Pão italiano, alface, tomate, } \\
\text { cebola, pimentão e azeitonas: } 912,5 \\
\mathrm{mg} \\
{ }^{*} \text { Carne: } 1028 \mathrm{mg}\end{array}$ & $2153,5 \mathrm{mg}$ \\
\hline $\begin{array}{l}\text { Fast-food com brinde (composto por } \\
\text { lanche, batata frita, fruta e suco em } \\
\text { porções compatíveis com o consumo } \\
\text { infantil) }\end{array}$ & $\begin{array}{l}\text { * Sanduíche: } 434 \mathrm{mg} \\
\text { * Fritas: } 94 \mathrm{mg} \\
\text { * Fruta: } 0 \mathrm{mg} \\
\text { * Suco - pêssego: } 11 \mathrm{mg}\end{array}$ & $539 \mathrm{mg}$ \\
\hline $\begin{array}{l}\text { Fast-food: refeição completa e suco } \\
\text { compatíveis ao consumo infantil + } \\
\text { brinde }\end{array}$ & $\begin{array}{l}\text { * Arroz: } 389 \mathrm{mg} \\
\text { * Feijão: } 223 \mathrm{mg} \\
\text { * Iscas de filé de frango: } 514 \mathrm{mg} \\
\text { * Salada de alface e tomate: } 3,8 \mathrm{mg} \\
\text { * Suco - pêssego: } 7,2 \mathrm{mg}\end{array}$ & 1137 mg \\
\hline
\end{tabular}

Fonte: Os autores, 2011.

O cloreto de sódio é bastante utilizado na indústria e adicionado em altas doses nos produtos com o intuito de realçar o sabor e preservar os alimentos. Grande parte dos produtos industrializados possuem quantidades significativas de sal (MOLINA et al., 2003).

O consumo excessivo de sódio está intimamente ligado à elevação da pressão arterial (MALACHIAS et al. 2016). A hipertensão arterial, proveniente desse consumo elevado, está associada ao aumento do risco de desenvolvimento de doenças cardiovasculares, que representam (ou que são) uma das maiores causas de mortalidade no Brasil (SOUZA et al., 2016).

Com relação aos açúcares, na legislação não há como obrigatoriedade detalhar os tipos de carboidratos que compõem o produto. Mas, na RDC 259 de 20 de setembro de 2002 (BRASIL, 2002), o item 6.2.2 exige que "a) todos os ingredientes devem constar em ordem decrescente, da respectiva proporção". Por isso, analisando a lista de ingredientes descrita na embalagem, é possível verificar que a maioria dos produtos alimentícios apresenta o açúcar como um dos três primeiros ingredientes (75\% dos alimentos e todas as bebidas). Esse dado revela o quanto esse ingrediente é utilizado nos produtos e que, apesar de não constar a informação em valores exatos, pode-se concluir que este compõe consideravelmente os alimentos em questão. 
Evidências indicam a relação existente entre a ingestão elevada de açúcar pela população em todo o mundo e o desenvolvimento de doenças crônicas, como cárie, obesidade, diabetes e câncer. Esse consumo excessivo também pode gerar ingestão abusiva e dependência de açúcar (GONÇALVES; PECHANSKY; SLAVUTZKY, 2011).

Ainda, ao analisar os ingredientes relatados das bebidas e o cumprimento da legislação, o refrigerante apresentado é considerado de baixo teor nutricional, uma vez que em sua composição há como ingrediente a cafeína, uma substância que atua como estimulante do Sistema Nervoso Central. É importante comentar também que muitas das tabelas nutricionais apresentadas na rotulagem têm um cálculo irreal de consumo se considerar o peso líquido do produto. É válido ressaltar que os comerciais não têm até o momento, a obrigatoriedade de alertar sobre essas informações, devido ao artigo 6을 RDC ํo 24 (BRASIL, 2010) permanecer suspenso.

Em matéria publicada na Folha de São Paulo, em março/2016, por veredito concebido em consenso pelos membros da ABIR (Associação Brasileira das Indústrias de Refrigerantes e Bebidas não Alcoólicas), não serão mais apresentadas propagandas de refrigerantes e sucos artificiais direcionadas para crianças até 12 anos. Sendo assim, esta suspensão é válida para canais que possuem mais que $35 \%$ de telespectadores com programação voltada para esse público. Além disso, a Abir também está analisando se é viável proibir a venda de bebidas com alto teor de açúcar para cantinas escolares no Brasil.

Essas medidas vêm sendo intensificadas após o surgimento, em 2014, do CONANDA, conselho ligado à Presidência, "considerar abusiva qualquer publicidade para crianças". Apesar dos resultados serem observados após essa pressão, os fabricantes se defendem, afirmando que as ações tomadas vêm ao exemplo de outros países.

Pelo descrito no CONAR, órgão este que tem como objetivo a promoção da liberdade de expressão publicitária e a defesa dos direitos constitucionais das propagandas, "os anúncios devem valorizar a prática de atividade física". Entretanto, grande parte das propagandas presentes neste estudo não remete em algum momento à exigência desse item, tendo como exceção os seguintes comerciais:

- O comercial dos minibolos (dois produtos) teve como cenário uma escola e a cena de crianças jogando bola;

- Do chocolate que é oferecido às crianças pela mãe num playground;

- Do suco artificial realizado com um grupo de adolescentes que se unem para reciclar objetos;

- Do cereal matinal, que remete à obtenção de energia pela ingestão do produto para as atividades do dia-a-dia (adolescentes jogando basquete). 
A omissão de algumas informações também podem gerar certa confusão quanto à origem do produto e o seu valor nutricional, havendo como exemplo o comercial de um dos salgados que tem como destaque ser um produto assado, feito com óleo de girassol e que está com redução igual a $25 \%$ de gordura saturada e sódio. Nos dados analisados, a gordura saturada desse produto é igual a $4,3 \mathrm{~g}$ e de sódio $330 \mathrm{mg}$ na porção de $100 \mathrm{~g}$, valores estes muito próximos aos considerados elevados.

Pelas análises realizadas, ainda foi observado que alguns anunciantes se utilizam de cenas um tanto quanto apelativas, como a criança saboreando o produto ou o chocolate sendo despejado, para atrair e convencer o seu público-alvo.

Os comerciais de alimentos exibidos na televisão têm sido considerados um dos principais responsáveis pelos índices elevados de DCNT, por exercerem influência nos hábitos e preferências alimentares da população.

Contudo, vale ressaltar que diversos fatores podem gerar influência nas escolhas alimentares e, por isso, considerar esse fato isoladamente, não trará importantes e significativos resultados a curto ou médio prazos, sendo que os pais têm fundamental importância na adoção de hábitos saudáveis dos seus filhos. Durante o processo de desenvolvimento neuropsicomotor da criança, os pais e mães são referências para serem seguidos e imitados. Nesse contexto, mudanças de hábitos que envolvam os familiares, como realizar as refeições à mesa ou a prática de atividades físicas em conjunto, sejam elas desportivas, sejam passeios alternativos aos finais de semana, pode evitar que o público infanto-juvenil permaneça recluso e tenham hábitos sedentários, como assistir TV ou ficar muitas horas do dia em frente ao computador (PONTES, et al., 2009).

Atualmente, está suspenso o artigo 6을 Capítulo III da RDC no 24 (BRASIL, 2010), sendo este referente à obrigatoriedade das empresas que possuam produtos com elevadas quantidades de açúcar, gordura saturada, de gordura trans, de sódio e de bebidas com baixo teor nutricional de incluírem alertas nas propagandas, publicidade ou promoção comercial de alimentos.

\section{CONCLUSÃO}

Pôde-se verificar, segundo os dados obtidos, que estes anúncios, ainda que não integrem o grupo com maior número de exibições, merecem análise individual, pois os produtos apresentam elevadas quantidades de açúcar e gorduras (saturada e trans). Além dos problemas com os alimentos, devem-se destacar os refrigerantes, que são considerados bebidas de baixo teor nutricional e por conterem, em sua lista de ingredientes, a cafeína. 
Diante das exigências impostas pelo CONAR, a grande maioria das propagandas avaliadas não apresenta como incentivo a prática de atividade física especificamente, e uma delas apresenta ainda certa confusão quanto à sua composição e valor nutricional.

Apesar da legislação relacionada à publicidade e propaganda destinadas ao público infantil ter alcançado significativos avanços, vê-se a necessidade de mais fiscalização e controle por parte dos órgãos públicos com relação às propagandas e inserções exibidas na televisão, uma vez que a quantidade exposta pode exercer considerável influência nas escolhas alimentares, principalmente no público infantil, etapa esta na qual a formação destas e as preferências alimentares estão sendo construídas.

\section{REFERÊNCIAS}

BRASIL. Agência Nacional de Vigilância Sanitária (ANVISA). Resolução - RDC no 259, de 20 de setembro de 2002. Disponível em: <http://www.anvisa.gov.br>. Acesso em: 08 out. 2011.

BRASIL. Agência Nacional de Vigilância Sanitária (ANVISA). Resolução - RDC no 24, de 15 de junho de 2010. Disponível em: <http://www.anvisa.gov.br>. Acesso em: 08 out. 2011.

BRASIL. Lei no 8.242 de 12 de outubro de 1991. Cria o Conselho Nacional dos Direitos da Criança e do Adolescente (Conanda) e dá outras providências. Diário Oficial da União, Brasília, 1991. Disponível em: <http://www.planalto.gov.br/ccivil_03/leis/l8242.htm>. Acesso em: 08 out. 2011.

CAVALHEIRO, C. V. et al. Composição química de folhas de oliveira (Olea europaea L.) da região de Caçapava do Sul, RS. Ciência Rural, v. 44, n. 10, p. 1874-79, out., 2014.

COMITÊ PERMANENTE DE NUTRIÇÃO DO SISTEMA DAS NAÇÕES UNIDAS (SCN). Declaração preliminar do grupo de trabalho sobre Nutrição, Ética e Direitos Humanos e Nutrição ao Longo do Ciclo de Vida. Brasil, 2006.

CONSELHO NACIONAL DE AUTORREGULAMENTAÇÃO PUBLICITÁRIA (CONAR). Novas normas éticas: publicidade de alimentos e refrigerantes, 2006. Consulta pública. Disponível em: <http://www.conar.org.br>. Acesso em: 08 out. 2011.

CONSELHO NACIONAL DOS DIREITOS DA CRIANÇA E DO ADOLESCENTE (CONANDA). Resolução - RDC $n^{\circ}$ 163, de 13 de março de 2014. Disponível em: $<$ http://pesquisa.in.gov.br/imprensa/jsp/visualiza/índex.jsp?jornal=1\&pagina $=4 \&$ data $=0$ 4/04/2014>. Acesso em: 17 fev. 2016.

DIAS, L. F. Propagandas de alimentos infantis com personagens e super-heróis em histórias em quadrinho. In: DIVERSIDADES E (DES)IGUALDADES, 07-10 ago. 2011, Salvador: In: CONGRESSO LUSO AFRO BRASILEIRO DE CIÊNCIAS SOCIAIS, 11, Salavados, 2011. Anais..., UFBA: Salvador, 2011. 
GAGLIARDI, A. C. M.; FILHO, J. M.; SANTOS, R. D. Perfil nutricional de alimentos com alegação de zero gordura trans. Rev. Assoc. Med. Bras., v. 55, n. 1, p. 50-53, 2009.

GONÇALVES, F. A.; PECHANSKY, F.; SLAVUTZKY, S. M. B. Desenvolvimento de um Questionário de Frequência Alimentar (QFA-açúcar) para quantificar o consumo de sacarose. Rev. HCPA, v. 31, n. 4, p. 428-436, 2011.

HENRIQUES, P. et al. A regulamentação da propaganda de alimentos no Brasil: convergências e conflitos de interesses. Cad. Saúde Pública, Rio de Janeiro v. 30, n. 6, p. 1219-1228, jun., 2014.

MALACHIAS, M. V. B. et al. 7ª Diretriz Brasileira de Hipertensão Arterial. Rev. Bras. Cardiol. Rio de Janeiro, v. 107, n. 3, supl. 3, set., 2016.

MOLINA, M. C. B. et al. Hipertensão arterial e consumo de sal em população urbana. Rev. Saúde Pública, São Paulo, v. 37, n. 6, p. 743-750, 2003.

MOZAFFARIAN, D. et al. Trans fatty acids and cardiovascular disease. N Engl Med., v. 354, p. 1601-1613, 2006.

PONTES, T. E. et al. Orientação nutricional de crianças e adolescentes e os novos padrões de consumo: propagandas, embalagens e rótulos. Rev. Paulista Pediatr. v. 27, n. 1, p. 99-105, 2009.

SILVA, D. A. C. et al. Publicidade de alimentos para crianças e adolescentes: desvelar da perspectiva ética no discurso da autorregulamentação. Ciênc. Saúde Coletiva, Rio de Janeiro, v. 22, n. 7, jul.2017.

SILVEIRA, M. das G. G. Prevenção da obesidade e de doenças do adulto na infância. Rio de Janeiro: Vozes, 2015.

SOUZA, A. M. et al. Impacto da redução do teor de sódio em alimentos processados no consumo de sódio no Brasil. Cad. Saúde Pública, Rio de Janeiro, v.32, n.2, fev.,2016.

VIVARTA, V. Infância e Consumo: estudos no campo da comunicação. Brasília: ANDI, Instituto Alana, 2009, 160 p. 